\title{
Hacia un concepto específico de lo político. Convergencias y divergencias entre las propuestas de Schmitt y Hinkelammert
}

Herrera Torres, Hugo Amador; Aguirre Ochoa, Jerjes Itzcoalt

Hacia un concepto específico de lo político. Convergencias y divergencias entre las propuestas de Schmitt y Hinkelammert

CIENCIA ergo-sum, vol. 25, núm. 3, noviembre 2018-febrero 2019 | e24

Universidad Autónoma del Estado de México, México

Esta obra está bajo una Licencia Creative Commons Atribución-NoComercial-SinDerivar 4.0 Internacional.

Herrera Torres, H. A. y Aguirre Ochoa, J. I. (2018). Hacia un concepto específico de lo político. Convergencias y divergencias entre las propuestas de Schmitt y Hinkelammert. CIENCIA ergo-sum, 25(3). https://doi.org/10.30878/ces.v25n3a2 


\title{
Hacia un concepto específico de lo político. Convergencias y divergencias entre las propuestas de Schmitt y Hinkelammert
}

\author{
Towards defining a specific concept of politics. Convergences and divergences between the proposals of Schmitt and \\ Hinkelammert
}

Hugo Amador Herrera Torres

Universidad Michoacana de San Nicolás de Hidalgo,

México

hugoht@fevaq.net

Jerjes Itzcoalt Aguirre Ochoa

Universidad Michoacana de San Nicolás de Hidalgo,

México

jerjes_99@yahoo.com

\section{Resumen:}

Se analiza la recepción del concepto de lo político de Schmitt en el realismo político de Hinkelammert. Al relacionar ambas propuestas, el planteamiento de Schmitt debe reformularse en buena medida. El concepto de lo político de Schmitt tiene dos partes: identificar al enemigo y enfrentarlo. La primera, en el realismo político de Hinkelammert, es aceptada de manera parcial; la segunda es rechazada por completo. Schmitt señala a las instituciones como el enemigo, en tanto que Hinkelammert indica que las instituciones absolutizadas son el enemigo. Ambos autores coinciden -relativamente- en quién es el enemigo, y señalan la necesidad de procesos instituyentes constantes para mantener el orden social. En la forma de operar estos procesos imperan las divergencias.

Palabras Clave: lo político, realismo político, realpolitik, enemigo, institución.

\section{ABstract:}

The paper analyzes the reception of the political concept of Schmitt in the political realism of Hinkelammert. In relating both proposals, Schmitt's approach must be reformulated in great extent. The political concept of Schmitt has two parts: identifying the enemy and confronting him. The first, in the political realism of Hinkelammert, is accepted in a partial way, the second is completely rejected. Schmitt points institutions as the enemy, Hinkelammert indicates that absolutized institutions are the enemy. Both authors coincide - relatively- who the enemy is, also point out the need for constant institutional processes to maintain social order. Divergences prevail in the form of operating these processes.

KEYWORDS: the political, political realism, realpolitik, enemy, institution.

\section{INTRODUCCIÓN}

Lo político hace referencia -en términos generales- al proceso que busca fijar las bases del orden social, es decir, a la determinación de los fundamentos sociales, a la construcción de los cimientos de una sociedad para un periodo específico, a la constitución de los principios rectores de la comunidad. Las bases del orden, los fundamentos sociales, los cimientos de una sociedad o los principios rectores quedan plasmados en las instituciones. ${ }^{[1]}$ Lo político tiene una relación con lo instituyente. La política, por su parte, corresponde a las acciones colectivas que buscan alcanzar -en la medida de lo posible- lo fijado con lo político (lo establecido en las instituciones). La política está vinculada con lo instituido. La política queda entonces condicionada por el contenido generado con lo político.

En el núcleo del concepto de lo político de Schmitt se encuentra la relación amigo-enemigo. Schmitt señala que los amigos y enemigos se forman con base en la aceptación o rechazo a las instituciones. El enemigo es la institución (Herrera, 2015). Lo político, para Schmitt, está exclusivamente en lo instituyente: transformación permanente de las instituciones. La política, en la argumentación schmittiana, consiste en la 
puesta en marcha de lo ordenado por las instituciones. Se trata de relaciones amigo-amigo. Hinkelammert, en su realismo político, otorga también un papel preponderante a las instituciones, subraya que las sociedades no pueden funcionar sin éstas. El realismo político hinkelammertiano, en sí, supera el tema de lo político; su propuesta también contiene la idea de política. Hinkelammert -de igual manera que Schmitthace énfasis en los cambios institucionales constantes.

En este artículo se busca identificar las convergencias y divergencias entre los planteamientos de Schmitt y Hinkelammert. Las aportaciones sobre lo político de ambos autores se concentran en el análisis institucional. Así pues, en el artículo tampoco se puede considerar una plataforma teórica más amplia para releer el concepto de lo político de Schmitt, donde se consideren, por ejemplo, las contribuciones de Badiou, Habermas, Castoriadis, Lefort, Arendt, Rancière o Laclau, porque -en sentido estricto- no hay correspondencia suficiente con el realismo político de Hinkelammert, incluso algunos de estos autores sugieren esquemas teóricos - hasta cierto punto- diferentes. La política de la liberación de Dussel y las tesis de Lechner sí tienen puntos directos de relación con el trabajo de Hinkelammert. El contexto histórico en el que Schmitt expuso su concepto y en el que Hinkelammert abrió el realismo político no limita el uso de ambas propuestas, ya que tienen carácter ubicuo. Schmitt, incluso, buscó desterritorializar y generalizar su concepto de lo político. ${ }^{[2]}$

Lo político, en el diseño teórico de Hinkelammert, tiene una racionalidad específica: racionalidad de vida. Lo racional es lo real y lo real es la corporalidad viviente. ${ }^{[3]} \mathrm{El}$ objetivo, entonces, de lo político está en crear las bases que permitan conservar y acrecentar la corporalidad viviente (Dussel, 2006; Herrera et al., 2016). En el realismo político de Hinkelammert subyace la ontología del querer-vivir. El querer-vivir se afirma como voluntad-devivir. La voluntad-de-vivir expresa el querer y seguir manteniendo la corporalidad viviente. La voluntad-de-vivir es la tendencia originaria de todos los seres humanos (Dussel, 2006). Esta idea, por lo menos, la proyectan con alto nivel de coincidencia Hinkelammert, Dussel y Lechner. El ser humano en el realismo político hinkelammertiano debe hacer empíricamente sólo lo posible. Lo posible empírico corresponde a todo aquello que es compatible con la regeneración de la corporalidad viviente. Lo posible empírico se determina a partir de lo imposible empírico. En el planteamiento de Hinkelammert se dibuja a la acción política como arte de lo posible. La misma condición humana señala los límites de lo posible empírico. Estos límites delinean un marco cerrado, el cual señala el espacio para realizar las acciones posibles. El límite de todos los límites es la terminación de la corporalidad viviente (muerte) (Hinkelammert y Mora, 2014). Los límites del marco equivalen a hechos fundantes. Los hechos fundantes son afirmaciones dadas e irrefutables, no tienen categoría de hipótesis, son aseveraciones que, de no presentarse, provocan la muerte del ser humano (Hinkelammert, 2000; Herrera, 2015):

a) La corporalidad viviente presupone la existencia del entorno natural.

b) Mantener la corporalidad viviente depende de la satisfacción de las necesidades existenciales físicas.

c) El ser humano requiere que los otros seres humanos satisfagan sus necesidades corporales para mantener su propia existencia.

Las acciones posibles son propiamente acciones políticas. En la realpolitik se realizan acciones incompatibles con la regeneración de la corporalidad viviente. Se trata de actividades que caen fuera de lo posible empírico, fuera del marco. La concreción del realismo político de Hinkelammert está, por consiguiente, en el marco de la posibilidad empírica (marco de acciones políticas). Los diversos puntos de variación que se forman dentro de este marco permiten la regeneración de la corporalidad viviente (Herrera, 2015; Herrera y Toledo, 2014). Las acciones fuera de la posibilidad empírica son propiamente acciones no políticas. Maquiavelo, Bismarck, Kissinger, Aron, Morgenthau han manejado la noción de realismo político y sus versiones -atendiendo a la propuesta de Hinkelammert-aterrizan en la realpolitik.

El realismo político de Hinkelammert anota que las instituciones son las encargadas de llevar las acciones humanas hacia el espacio de la posibilidad empírica; no obstante, las instituciones tienen funcionamiento imperfecto, cláusulas de temporalidad y, además, el ser humano tiende a absolutizarlas de manera inevitable. 
La absolutización es el método que invierte de manera radical las posiciones y conductas. Las instituciones atravesadas por este método llevan las acciones humanas hacia la imposibilidad empírica.

Los procesos que presentan Schmitt y Hinkelammert tienen diferencias marcadas. Hipotéticamente, el concepto de lo político de Schmitt rompe los límites del marco de la posibilidad empírica. Las convergencias y divergencias entre las propuestas de Schmitt y Hinkelammert ayudan a generar puntos que aproximen a un concepto específico de lo político. En el proceso está la especificidad. El debate no está en reconceptualizar lo político sino en la identificación de las líneas básicas (partes o elementos) del proceso que se sigue en lo político.

\section{Materiales y MÉtodos}

\section{1. El concepto de lo político de Schmitt: bases y partes interrelacionadas ${ }^{[4]}$}

Lo político, siguiendo a Schmitt (2009), tiene categorías específicas y autónomas: amigo y enemigo. La relación amigo-enemigo, en la explicación de este autor, expresa el máximo grado de separación o diferencia entre dos polos: un polo niega la existencia de otro polo. La diferencia se origina a partir de la regulación formal dada a los hechos sociales. La forma que adquieren los hechos sociales es generada entonces por las instituciones. El enemigo está en las instituciones.

La institución no es empírica; empero, indica las bases para lo empírico. La relación de enemistad se da contra las organizaciones que instalan, defienden y siguen determinadas instituciones. La institución para operarse y tener representación objetiva necesita de organizaciones. La institución y las organizaciones, en conjunto, constituyen una unidad política. El ejemplo más representativo de una unidad política es el Estado. El enemigo objetivo está entonces en las organizaciones. El enemigo, en términos generales, corresponde a una unidad política. Pero el germen que produce la enemistad está en la institución. ${ }^{[5]}$

Una unidad política puede buscar mantener una institución. Se trata de la defensa de lo instituido. Una unidad política puede proyectar también la creación de nuevas instituciones. Se trata de ejercer lo instituyente. Para Schmitt existe una tensión continua entre lo instituido y lo instituyente, donde es latente el peligro de llegar a puntos extremos de quiebre; llegando a estos puntos, se produce la relación amigoenemigo. Lo instituyente es efecto directo de la decisión autónoma de los grupos sociales para conformar una unidad política. La relación amigo-enemigo siempre será conflictiva. El concepto de lo político de Schmitt así tiene dos partes interrelacionadas: $a$ ) identificar al enemigo y $b$ ) enfrentarlo.

Schmitt (2009) enfatiza que el enemigo no es un opositor del gobierno, ya que el opositor participa y acata la institucionalidad imperante; el opositor busca ocupar los espacios de la organización gubernamental. Schmitt califica a esta correspondencia (opositor del gobierno) como relación amigo-amigo, pues su comportamiento sigue a las instituciones. El enemigo hace referencia a una unidad política que se enfrenta -en un terreno imparcial, sin regulación impuesta por terceros- a otra unidad política que se le opone y niega su existencia. La relación amigo-enemigo -en la argumentación schmittiana- no está sujeta a ninguna institución, porque la disputa es, para un polo, mantener las instituciones vigentes y, para el otro, introducir nuevas instituciones.

El periodo de cambio institucional, representa para Schmitt, el estado de excepción. La decisión soberana de una unidad política para anular a otra unidad política da entrada al estado de excepción. Se trata de un momento histórico de modificación total-parcial o reafirmación de la institucionalidad imperante.

A las relaciones amigo-amigo, Schmitt las conecta con la política. Son relaciones que no generan contraposición, sólo tienen grados de amistad. Schmitt (2009) hace énfasis que ante la falta de la relación amigo-enemigo desaparece la pluralidad de unidades políticas. Una unidad política presupone entonces la existencia de otras unidades políticas. Lo político anota un pluriverso. Una unidad política única y total (universo) advierte una despolitización. 
La relación amigo-enemigo, en el concepto de lo político de Schmitt, se atiende en un enfrentamiento real. El enfrentamiento es un combate, y el combate forma parte de la guerra. La guerra es la enemistad hecha efectiva. Schmitt habla de la guerra como postura y como acción.

a) La postura de guerra implica que una unidad política se mantenga vigilando al enemigo vencido e identificando a los nuevos enemigos. La guerra como postura es permanente.

b) La guerra como acción corresponde a los combates. El combate debe ser entendido en su forma original: contienda violenta para domesticar al enemigo. Domesticar hace referencia a desarmarlo, buscar su rendición, dominarlo. Ganar la guerra -o el conjunto de combates que constituyen a la guerra- no es propiamente eliminar al enemigo, aunque la eliminación puede ser alternativa en situaciones especiales. Ganar la guerra, según Schmitt (2009), tampoco consiste en neutralizar al enemigo, borra la relación amigo-enemigo, ya que se disipa la posición de enemigo. La guerra como acción es eventual.

La guerra retrata al concepto de lo político de Schmitt. Lo político es la guerra en su conjunto. La guerra como postura corresponde a la primera parte del concepto y la guerra como acción a la segunda parte. Schmitt insiste en justificar que la amistad está subordinada a la relación amigo-enemigo. Apunta que si sobre la Tierra existiera sólo amistad, sería el final simultáneo de la enemistad y amistad, ya que para definir quiénes son amigos se necesita -a la vez- definir quiénes son enemigos. Identificar al enemigo (guerra como postura) es imprescindible para la paz. Combatir al enemigo (guerra como acción) es indispensable para la paz. Para Schmitt, la guerra -con sus dos partes (postura y acción) - es el camino hacia la paz o, lo que es lo mismo, lo político lleva hacia la paz.

Schmitt (2009) señala que desarrollar la guerra bajo la consigna de que será la última guerra, en busca de la paz eterna, implicaría una guerra - por necesidad- violenta, porque transponiendo lo político se transformaría al enemigo en una bestia feroz, el cual no sólo debe ser encerrado en sus límites (domesticado), sino eliminado. El enemigo se convertiría en enemigo absoluto.

La tarea del Estado, continuando con la explicación schmittiana, consiste en lograr la paz en su territorio. Las instituciones tienen ese objetivo. En los conceptos tradicionales de lo político, los comportamientos de los grupos sociales que siguen a las instituciones son aceptados. Los comportamientos que las desafían son anormales y, por tanto, deben eliminarse, pues atentan contra la paz. La necesidad de lograr la pacificación conduce a que el Estado -como unidad política- determine a sus enemigos. Estos enemigos, atendiendo a Schmitt, son enemigos absolutos.

\section{Resultados y Discusión}

La primera parte del concepto de lo político de Schmitt es aceptada parcialmente en el realismo político de Hinkelammert. Existen convergencias y divergencias: ${ }^{[6]}$

a) ¿De dónde surgen las instituciones? Schmitt es explícito en la respuesta: del poder instituyente. El poder instituyente surge con las unidades políticas que buscan la reorientación institucional. Schmitt saca conclusiones: el acto de instituir no agota ni suprime al poder instituyente; de suceder, lo político desaparece. El realismo político de Hinkelammert no desecha la idea schmittiana sobre el poder instituyente, considera también al poder instituido como parte esencial del desarrollo político.

Schmitt identifica que la institución es el enemigo, sitúa la relación amigo-enemigo en el núcleo de lo político. Hinkelammert también pone atención especial en las instituciones, ya que las considera como los medios que deben proteger la corporalidad viviente. El ser humano que conforma a los grupos sociales, según el realismo político hinkelammertiano, por su misma condición, absolutiza a las instituciones, el cambio de éstas, por tanto, debe ser constante. Las instituciones absolutizadas, en Hinkelammert, en efecto, son también el enemigo. 
b) Schmitt acepta las relaciones amigo-amigo (la política) y les concede periodicidad restringida. El realismo político acepta las relaciones amigo-amigo mientras éstas permanezcan dentro del marco de acción política. Las reconoce también como temporales.

c) La imagen de enemigo absoluto enfocada por Schmitt es aceptada -de forma parcial- por Hinkelammert. Schmitt señala que la transformación de su relación amigo-enemigo hacia su extremo de amigo-enemigo absoluto puede darse. El enemigo absoluto es rebajado a una posición inhumana, es decir, la unidad política es considerada una bestia feroz. Su eliminación se hace inminente. El mismo Hinkelammert (1990) apunta que cabe acertadamente la imagen de enemigo absoluto de Schmitt para describir el "desarme moral" que vivió América Latina en la década de los setenta del siglo pasado. Hinkelammert (1990) señala que dicha absolutización llevó a grados insoportables/intolerantes/inhumanos al conflicto. El realismo político hinkelammertiano coincide con las consecuencias - planteadas por Schmitt- que trae el método de la absolutización. Se puede enunciar, siguiendo este planteamiento, que la unidad política que absolutiza a las instituciones (amigo absoluto) pide la eliminación de las unidades que se oponen a éstas. La absolutización del amigo genera entonces enemigos absolutos.

d) Schmitt no identifica que la formación del enemigo absoluto proviene de la absolutización del otro polo. En la relación amigo-enemigo, donde uno niega la existencia de otro y viceversa, indica que las posturas de los polos se han absolutizado. El mismo Schmitt, incluso, crea una nueva imagen de enemigo absoluto. Se trata de aquellos que no aceptan su relación amigo-enemigo. El jurista alemán, sin darse cuenta, absolutizó la relación amigo-enemigo. Sus enemigos absolutos son aquellos que antes creaban imágenes de enemigos absolutos (Hinkelammert, 1990).

e) El estado de excepción que plantea Schmitt no es aceptado en el planteamiento de Hinkelammert. El primero que denunció al estado de excepción como regla para el cambio institucional fue Walter Benjamin (Hinkelammert, 2013). En el estado de excepción se sobrepasan los límites que delinean al marco de acciones posibles y llevan las actividades hacia la imposibilidad empírica. En ningún estado de excepción se protege la corporalidad viviente. El estado de excepción es uno de los ejemplos más representativos de la realpolitik. El cambio institucional llevado a cabo sin arbitrajes sólo cabría en ocasiones específicas y eventuales en la propuesta de Hinkelammert. Estas ocasiones corresponden a las revoluciones. Las revoluciones son acontecimientos políticos, pero no son regla para el cambio institucional. Las revoluciones adquieren un excepcional estatus instituyente, no asimilable a un acto de mera violencia (Retamozo, 2009).

f) Schmitt proyecta una destrucción social en tanto se busque perpetuar la relación amigoamigo. La perpetuación de la relación amigo-enemigo, para él, no llevaría a esta destrucción. En el realismo político de Hinkelammert, la absolutización de cualquier tipo de estas relaciones paraliza el desarrollo político.

g) La argumentación de Schmitt hace pensar que el cambio institucional sólo puede concretarse/ materializarse desde el Estado: que la unidad política vencedora en el enfrentamiento asuma el control de las organizaciones gubernamentales y -estando ahí- instale formalmente las instituciones que venía construyendo y promoviendo desde el estado de excepción. Empero, para la modificación institucional no es necesario estar en las organizaciones gubernamentales. Ante la absolutización de las instituciones, surgen movimientos sociales (unidades políticas) que pueden asumir la responsabilidad de combatir la dominación mediante la resistencia y la presión. Los movimientos sociales de resistencia pueden ser el contrapeso que logre cambios institucionales (Gallardo, 1992; Duarte, 1994). 
b) Schmitt apunta que la neutralización del enemigo elimina a la propia neutralidad, porque el enemigo neutralizado ya no tiene opciones para adoptar posiciones. Sólo tiene una alternativa y, por consiguiente, deja de ser enemigo. Al tratarse de neutralidad estática, el enemigo se transforma en amigo. En la neutralización dinámica, el enemigo deja de ser enemigo "momentáneamente", luego recobra su posición. Hinkelammert subraya que siempre hay opciones (alternativas). Por carencia/ ausencia de opciones (alternativas), la neutralidad, ya sea estática o dinámica, nunca se borra. El mismo Schmitt, sin darse cuenta, contradice su comentario. Un enemigo -en la neutralización dinámicadecide adoptar un enfoque de reorganización para activar su papel de unidad política, pero también puede decidir incorporarse a la unidad política imperante (neutralidad estática). No obstaculizar ni limitar la operación de una unidad política significa apoyar a esa unidad política. A final de cuentas, en este contexto, el enemigo toma la decisión de ingresar a la neutralidad dinámica o estática. El ser humano no sería humano, si no tuviera siempre opciones (Hinkelammert, 1999).

La segunda parte del concepto de lo político de Schmitt es rechazada por completo en el realismo político de Hinkelammert. La reformulación de esta parte implica anular la guerra como acción (combates bélicos). Las unidades políticas actúan en el interior del marco de la posibilidad empírica. Los combates provocan que se rompa este marco y se desplazan así las acciones hacia el espacio de la imposibilidad empírica. Los combates como acción sistemática no son, por consiguiente, acciones políticas.

Las unidades políticas mantienen relación constante con las otras: son necesariamente interdependientes. El mismo Schmitt señala que la existencia de una unidad política presupone la presencia de otra u otras unidades políticas (pluriverso). Considerar la interdependencia de las unidades políticas hace que la guerra como acción deje de ser un medio político y se transforme en una herramienta de autodestrucción. Por más que exista el enemigo como enemigo real (enemigo rendido, dominado o desarmado) es latente su eliminación en situaciones de combate y se hace posible la formación de una unidad política única y total (universo). Schmitt critica la existencia de una sola unidad política porque cancela su propuesta, pero su medio político (la guerra como acción) lleva hacia un universo. En el realismo político, destruir al otro sistemáticamente -vía combate o por cualquier otro medio- es autodestruirse porque se atenta contra un hecho fundante: el ser humano necesita de la existencia de los otros seres humanos para mantener su propia existencia. La guerra como acción está enmarcada en la realpolitik.

El concepto de lo político de Schmitt no se invalida en su totalidad, pero obliga a modificarlo. La posibilidad empírica se destruye con la confrontación bélica sistemática entre unidades políticas. Los combates deben sustituirse por otros medios políticos, cuya puesta en marcha no rompa el marco de acciones políticas. La práctica discursiva es un medio político que da la oportunidad de conjuntar las decisiones autónomas de los grupos sociales y hacer transformaciones institucionales sin alterar dicho marco. Los grupos sociales, conformados por entes comunicativos-lingüísticos, de modo recíproco, pueden reclamar su posición en el presente concreto, criticar la validez de las pretensiones de los otros, poner en orden las discrepancias y llegar a consensos. Lo mismo está implícito en la actuación de las unidades políticas. La enemistad o conflicto debe disciplinarse a la práctica discursiva, la cual alude a la producción de pensamientos y enunciados basados en la racionalidad de vida. Lechner (1986) en su planteamiento para la construcción del orden social (cambio y desarrollo institucional) también toma esta posición. Concibe un proceso de subjetivación: se debe enfrentar al otro no para domesticarlo ni para desarmarlo ni mucho menos para eliminarlo, sino para asumir la diferencia y lograr el reconocimiento mutuo. La subjetivación sólo es posible si existe el otro como referencia, no como amenaza existencial. El otro constituye la condición de la propia existencia.

Arendt (1997) continúa por la misma línea. Anota que los medios políticos corresponden a las prácticas discursivas en el tratamiento de asuntos comunes, y señala que el discurso permite presentarse ante los otros y establecer un espacio compartido en el que haya pluralidad e isonomia en busca de cambios institucionales. La práctica discursiva se envuelve entonces en un diálogo concertado, de persuasión y reconocimiento direccionado al actuar mancomunado (Retamozo, 2009). En esta práctica, la contingencia se manifiesta y no 
hay exención de tensiones (disputa y antagonismo). La práctica discursiva como medio político en la relación amigo-enemigo sustituye a los combates, y también está presente en la relación temporal amigo-amigo.

La práctica discursiva, en el realismo político hinkelammertiano, está cubierta de una racionalidad de vida. En Dussel (1998), de igual manera, el criterio de validez discursiva está en mantener la corporalidad viviente en los otros y de uno (sujeto). La consensualidad crítica de los afectados por las instituciones promueve la práctica discursiva a favor del desarrollo de la vida. Una unidad política busca entonces convertir la postura de otra unidad política que adopte una posición que permita que los movimientos se efectúen dentro de lo posible empírico. Si la unidad política sigue en la realpolitik después de exhaustivas prácticas discursivas, la eliminación pudiera ser una alternativa. La actividad de una unidad política en lo imposible empírico amenaza la existencia de todas las demás unidades políticas, incluyendo la suya. Esta eliminación probablemente equivale a una revolución. En las revoluciones las unidades políticas subordinan la práctica discursiva a la acción violenta justificada. Esta violencia no es mera violencia. La eliminación no puede tomarse como acción sistemática, permanente o perpetua, pues atenta contra los hechos fundantes.

Podría afirmarse a) que se está absolutizando al marco de acción política y b) que se está creando una nueva imagen de enemigo absoluto: eliminar a todos aquellos que no aceptan moverse dentro de la posibilidad empírica. Ambas afirmaciones son falsas. Se formaría, más bien, un enemigo testimonial. El enemigo, en el proceso de lo político debe enfrentarse usando la práctica discursiva -como medio políticoen busca de convertir su posición. La conversión usando el discurso invalida la imagen de enemigo absoluto. La opción de eliminar al enemigo además sólo es factible en situaciones que pongan en peligro la permanencia de las unidades políticas (situaciones extremas/terminales), que se justifica únicamente agotándose todas las opciones posibles para la conversión.

Otra reformulación del planteamiento de lo político de Schmitt está en su idea de paz eterna. Schmitt explica que la paz eterna como hecho prescindiría de lo político, no formándose más la relación amigoenemigo, por lo cual habría, por ende, sólo relaciones amigo-amigo. Schmitt, ante esto, anula a la paz eterna como categoría política (Hinkelammert, 1990). La relación amigo-enemigo transformada en relación pazguerra, en la argumentación schmittiana, no deriva en conflicto político, porque el enemigo sería una bestia feroz. Se trata de un enemigo absoluto y, los enemigos absolutos, deben eliminarse.

Schmitt (2009) le quita entonces cualquier tipo de relevancia teórica y práctica a la paz eterna. En el realismo político hinkelammertiano también la paz eterna no es un enemigo, sino una utopía. A partir de las utopías se desprenden las instituciones, las cuales sí pueden ser amigos o enemigos. El problema de Schmitt se encuentra en la posición que otorga a la paz eterna. Schmitt se adentra a la utopía sin conocerla. La utopía modela lo que debiera ser la sociedad. Schmitt no reconoce la relevancia teórica de la utopía. Ciertamente no es posible en la realidad; no obstante, es indispensable. Schmitt sin darse cuenta proyecta la utopía de la guerra eterna, lo contrario a la utopía de la paz eterna.

\section{Conclusiones}

La recepción del concepto de lo político de Schmitt en el realismo político de Hinkelammert es diversa. En la primera parte del concepto (identificar al enemigo) hay convergencias y divergencias. Sobre las convergencias principales, Schmitt identifica con acierto que la institución es el enemigo y sitúa la relación amigo-enemigo en el centro del análisis sobre lo político. Las instituciones absolutizadas, en Hinkelammert, son también el enemigo. En su realismo político explica que no se puede vivir sin las instituciones, pero tampoco se puede vivir sometido a ellas. Las instituciones - de forma irremediable- se absolutizan; estando en esta posición, dominan al ser humano. El cambio institucional debe ser constante para ambos autores. Schmitt también enfoca de forma apropiada, a partir del realismo político hinkelammertiano, la imagen de enemigo absoluto, pero no identifica que el enemigo absoluto viene de la absolutización del amigo. 
Sobre las divergencias principales: en la propuesta de Hinkelammert no se acepta que el tratamiento de la relación amigo-enemigo siempre tenga que desarrollarse fuera de las instituciones, sólo contempla esto para situaciones especiales (revoluciones). El estado de excepción que sugiere Schmitt también es rechazado. En otro punto, Schmitt hace interpretar que la modificación institucional se concreta cuando la unidad política se hace Estado. Los movimientos sociales de resistencia, en el planteamiento de Hinkelammert, pueden operar como unidades políticas de presión que obliguen a las organizaciones gubernamentales a realizar cambios institucionales.

La segunda parte del concepto de lo político de Schmitt se inscribe en la realpolitik. El realismo político hinkelammertiano llama acciones políticas a las acciones posibles empíricamente. El combate bélico rebasa los límites de la posibilidad empírica, las acciones de este tipo serían no políticas. Al considerar la interdependencia de las unidades políticas, los combates resultan medios de autodestrucción. El medio político para disolver la enemistad institucional está primeramente en la práctica discursiva. El criterio de validez de esta práctica está bien definido en las construcciones teóricas de Hinkelammert, Dussel y Lechner: mantener la corporalidad viviente (racionalidad de vida). Schmitt, además, no logró escapar de los peligros que denunciaba. Planteó que la formación de enemigos absolutos anulaba lo político, pero su propuesta sobre lo político genera enemigos absolutos. Schmitt criticó la existencia de una sola unidad política, ya que se necesita de varias unidades para mantener lo político, pero su medio (combate) de enfrentar a la otra unidad política conduce a la existencia de una sola unidad política.

Las relaciones amigo-amigo (la política) sólo tienen vigencia temporal, pues perennemente atraviesan por momentos de desgaste total o parcial. La política no está en el cumplimiento ciego del contenido de las instituciones, sino en los vínculos que los seres humanos (organizados en grupos sociales y en unidades políticas) entablen con ellas. El ser humano es político en tanto sepa relativizarlas y adecuarlas en función de la vida (racionalidad de vida). Los partidos políticos de izquierda, en específico, los que participan en procesos electorales formales han quedado atrapados en las relaciones amigo-amigo. Esto es parte del derrumbe de casi toda la izquierda en América Latina. De repente se volvieron amigos del otro bando. En algunos movimientos sociales de resistencia ha resurgido la relación amigo-enemigo: se trata de aquellos que aparecieron en nombre de la recuperación y ampliación de los derechos humanos que habían sido aplastados por las mismas instituciones.

\section{ANÁLISIS PROSPECTIVO}

En el artículo se consideran tres ideas que justifican la vigencia y pertinencia de estudiar el concepto de lo político. Primero, el problema no está en reconceptualizar lo político. Hay convergencia en las diversas propuestas teóricas que lo plantean; más bien, el objetivo está en identificar las fases del proceso que corresponde a lo político. Las divergencias entre los autores vienen precisamente de cuáles son estas fases y de cómo implementarlas. Segunda, las propuestas de Schmitt y Hinkelammert forman una base analítica para trazar directrices iniciales del concepto específico de lo político. Tercera, en América Latina el cambio institucional ha pasado a un segundo plano en el análisis político. Después de la Segunda Guerra Mundial y hasta los años setenta había en Latinoamérica aceptación, más o menos, suficiente de las instituciones, la cual permitía la existencia de Estados relativamente estables. La aceptación a veces era forzada porque la institución no estaba basada en acuerdos sociales sólidos, pero funcionaba. En los años setenta y ochenta reaparecieron los conflictos en relación con la vigencia institucional (Hinkelammert, 1990). Los Estados -respondiendo a las dinámicas expansivas mundiales del neoliberalismo- cambiaron sus cuadros institucionales. Otros grupos sociales se resistieron a esta nueva institucionalidad, pero reconocían que la vieja institucionalidad era caduca, sugerían vías marxianas o marxistas. El asunto decisivo estaba, por tanto, en la transformación institucional. Durante los años ochenta y noventa se consolidaron instituciones promotoras del modelo neoliberal. La mayoría de la acción política, desde entonces, se limitó prácticamente a lo marcado 
en éstas. Trajo como consecuencia que, en gran medida, la crítica institucional fuera secundaria (Herrera, 2015). Los esfuerzos, en la mayoría de los países de América Latina, en materia institucional tienen carácter de "reformas", no penetran en la esencia del contenido institucional. El debate sobre el cambio institucional debe estar en primer plano.

\section{REFERENCIAS}

Arendt, H. (1997). ¿Qué es la politica? Barcelona: Paidós.

Bohórquez, J. (2006). El poder constituyente, fundamento de la democracia: Carl Schmitt. Papel Político, 11(2), 525-556.

Cristi, R. (2008). La lección de Schmitt: poder constituyente, soberanía y principio monárquico. Revista de Ciencia Politica, 28(2), 17-31.

Delgado, M. (2001). El criterio amigo-enemigo en Carl Schmitt. El concepto de lo político como una noción ubicua y des-territorializada. Cuaderno de materiales 14. Disponible en http://www.filosofia.net/materiales/fnumero s.htm

Duarte, C. (1994). La resistencia de los jóvenes en un país capitalista pobre y dependiente. Pasos, 53, 6-30.

Duque, J. (2008). El concepto de lo politico en Carl Schmitt en movimiento: amigo-enemigo y guerra. Bogotá: Escuela de Ciencias Humanas, Universidad Colegio Mayor de Nuestra Señora del Rosario.

Dussel, E. (2006). 20 tesis de política. México: Siglo XXI.

Dussel, E. (1999). Sobre el sujeto y la intersubjetividad: el agente histórico como actor en los movimientos sociales. Pasos, 84, 2-15.

Dussel, E. (1998). Ética de la liberación en la edad de la globalización y la exclusión Madrid: Editorial Trotta.

Fijalkowski, J. (1996). La trampa ideológica del totalitarismo: análisis crítico de los componentes ideológicos en la filosofia politica de Carl Schmitt. Madrid: Tecnos.

Gallardo, H. (1992). Observaciones básicas respecto de actores sociales, movimiento popular y sujeto histórico en la América Latina de la década de los noventa. San José de Costa Rica: Departamento Ecuménico de Investigaciones (DEI). Inédito.

Herrera, H., Arias, D., y Colín, R. (2016). Lo político y la política. Desdoblamiento del poder político en la Política de la Liberación de Enrique Dussel. Economía y Sociedad, 20(35), 171-185.

Herrera, H. (2015). Realismo politico y realpolitik. Hacia una reconceptualización de lo politico. Contrastes entre Carl Schmitt y Franz Hinkelammert. Morelia: Universidad Michoacana de San Nicolás de Hidalgo.

Herrera, H., y Toledo, A. (2014). La política como arte de lo posible. Delimitación del marco de acción política a partir del realismo político de Franz Hinkelammert. Critica Contemporánea. Revista de Teoría Política, 4, 32-50.

Hinkelammert, F. (2013). La maldición quepesa sobre la ley. Las raices del pensamiento crítico en Pablo de Tarso (segunda edición). San José de Costa Rica: Arlekín.

Hinkelammert, F. (2000). Crítica a la razón utópica (tercera edición). San José de Costa Rica: DEI.

Hinkelammert, F. (1999). Ensayos. La Habana: Caminos.

Hinkelammert, F. (1990). Democracia y totalitarismo. San José de Costa Rica: DEI.

Hinkelammert, F. y Mora, H. (2014). Economía, vida bumana y bien común. 25 reflexiones sobre economía critica. Disponible en http://www.pensamientocritico.info/libros/libros-de-franz-hinkelammert/doc_details/31-econ omia-vida-humana-y-bien-comun-25-reflexiones-sobre-economia-critica.html

Jiménez, G. (2012). El concepto de política y sus implicaciones en la ética pública: reflexiones a partir de Carl Schmitt y Norbert Lechner. Revista Reforma y Democracia, 53, 215-238.

Lechner, N. (1986). La conflictiva y nunca acabada construcción del orden deseado. Madrid, Siglo XXI.

Manin, B. (2003). Carl Schmitt, ¿"el mejor enemigo del liberalismo"? Politica y gobierno, 10(2), 401-412.

Mouffe, C. (2002). Carl Schmitt y la paradoja de la democracia liberal. Tópicos, 10, 5-25. 
Sanromán, D. (2004). Carl Schmitt. La cuestión del poder. Nómadas. Revista Critica de Ciencias Sociales y Jurídicas, $10,1-21$.

Retamozo, B. (2009). Lo político y la política: los sujetos políticos, conformación y disputa por el orden social. Revista Mexicana de Ciencias Politicas y Sociales, 51(206), 69-91.

Schmitt, C. (2009). El concepto de lo político. Madrid: Alianza Editorial.

\section{Notas}

[1] No se considere a las instituciones como sinónimo de organizaciones gubernamentales. Las instituciones corresponden a las reglas formales (normatividad jurídica) que determinan la manera de gestionar/tratar los hechos sociales. Las instituciones también comprenden reglas informales, las cuales condicionan -al igual que las reglas formales- el comportamiento de los grupos sociales (Herrera, 2015). En este artículo se hace referencia exclusiva a las instituciones formales.

[2] No es objeto de estudio, en este documento la participación directa o indirecta de Schmitt en el Tercer Reich, el acercamiento se hace a su arco académico-conceptual.

[3] Dussel (1999) distingue entre corporeidad y corporalidad. El ser humano es un ser corporal vivo. Lo corporal vivo corresponde a la vida humana con su lógica propia. La corporalidad indica la esfera material del ser humano, la cual se distingue de la mera corporeidad animal. La corporalidad, hasta su última célula, es esencial y diferenciadamente humana.

[4] Una primera sistematización del concepto de lo político de Schmitt se hace en Herrera (2015).

[5] Varios autores que han estudiado el concepto de lo político de Schmitt identifican al enemigo en el Estado o en las organizaciones. Esto es correcto. Sin embargo, no hacen explícito dónde se halla la fuente de la discordia (las instituciones). Véase, por ejemplo, los trabajos de Jiménez (2012), Retamozo (2009), Duque (2008), Cristi (2008), Bohórquez (2006), Sanromán (2004), Manin (2003), Mouffe (2002), Delgado (2001) y Fijalkowski (1996).

[6] En esta sección se profundizan aspectos, se precisan otros y se corrigen algunas inconsistencias sobre el análisis que realizó Herrera (2015) respecto a la recepción del concepto de lo político de Schmitt en la producción teórica de Hinkelammert.

\section{BY-NC-ND}

